\title{
LCA Case Studies
}

\section{Allocation in LCA of Wood-based Products Experiences of Cost Action E9}

Part II. Examples

\author{
Gerfried Jungmeier ${ }^{1 *}$, Frank Werner ${ }^{2}$, Anna Jarnehammar ${ }^{3}$, Catharina Hohenthal ${ }^{4}$ and Klaus Richter ${ }^{2}$ \\ 1 JOANNEUM RESEARCH, Institute of Energy Research, Elisabethstrasse 5, A-8010 Graz, Austria \\ 2 Federal Laboratories for Materials Testing and Research (EMPA), Duebendorf, Switzerland \\ ${ }^{3}$ Trätek, Swedish Institute for Wood Technology Research, Stockholm, Sweden \\ 4 KCL, Helsinki, Finland
}

* Corresponding author (gerfried.jungmeier@ioanneum.at)

Preamble. The treatment of allocation is a crucial matter in the LCA of wood-based products, because the allocation method might influence the results significantly. This paper outlines in two parts - Methodology (Part I) and Examples (Part II) - practical experiences for the treatment of allocations for LCAs of wood-based products that are the result of the Cost Action $E 9$ 'Life cycle assessment of forestry and forest products' and reflect the experience of Cost E9 delegates. Part I has been published in the September issue [Int J LCA 7 (5) $290-294$ (2002)] [8a].

\section{DOI: http://dx.doi.org/10.1065/lca2002.08.091.2}

\section{Abstract}

Goal and Background. The treatment of allocation in the descriptive LCA of wood-based products has been discussed for a long time and different solutions have been presented. In general, it is accepted that the influence of different allocation procedures on the results of LCA of wood-based products can be very significant. This paper is a result of the Cost Action E9 'Life cycle assessment of forestry and forest products' and represents the experience of involved Cost E9 delegates.

Objective. Wood is a renewable material that can be used for wood products and energy production. Consistent methodological procedures are needed in order to correctly address the twofold nature of wood as a material and fuel, the multi-functional wood processing generating large quantities of co-products, and reuse or recycling of paper and wood. Ten different processes in LCAs of wood-based products are identified, where allocation questions can occur: forestry, sawmill, wood industry, pulp and paper industry, particle board industry, recycling of paper, recycling of wood-based boards, recycling of waste wood, combined heat and power production, landfill.

Methodology. Following ISO 14041 a step-wise procedure for system boundary setting and allocation are outlined. As a first priority allocation should be avoided by system expansion, thus adding additional functions to the functional unit. Alternatively, the avoided-burden approach can be followed by subtracting substituted functions of wood that are additionally provided. If allocation cannot be avoided, some allocations methods from case studies are described.

Conclusions. The following conclusions for allocation in LCA of wood-based products are given. 1) Avoid allocation by expansion of system boundaries by combining material and energy aspects of wood, meaning a combination of LCA of wood products and of energy from wood with a functional unit for products and energy. 2) Substitute energy from wood with conventional energy in the LCA of wood products to get the functional unit of the wood product only, but identify the criteria for the substituted energy. 3) Substitution of wooden products with non-wooden products in LCA of bioenergy is not advisable, because the substitution criteria can be too complex. 4) If avoiding allocation is not possible, the reasons should be documented. 5) Different allocation procedures must be analysed and documented. In many cases, it seems necessary to make a sensitivity analysis of different allocation options for different environmental effects. It can also be useful to get the acceptance of the chosen allocation procedure by external experts. 6) Different allocation factors, e.g. mass or economic value, are allowed within the same LCA. 7) For allocation of forestry processes it is necessary to describe the main function of the forest where the raw material is taken out. In some cases different types or functions of forests must be considered and described. 8) Regarding the experiences from the examples, the following most practical allocation for some specific processes are identified: forestry: mass or volume; sawmill: mass or volume and proceeds; wood industry: mass and proceeds.

Keywords: Allocation; bioenergy; forest products; forestry; Cost E9; life cycle assessment; wood products

\section{Introduction}

Examples from different case studies are outlined to substantiate the previous reasoning from Part I [Int ] LCA 7 (5) 290294 (2002)]. The examples are taken from LCA studies in which the authors were involved. The examples are given in an order following that of the wood chain. In two examples recycling of particle boards, combined heat and power production - an allocation is avoided; in the other examples, one or more different allocation procedures are applied. 


\section{Examples}

\subsection{Forestry}

Introduction. Allocation in forestry means to allocate the environmental effects from forest management to the different co-products of forestry. Forest management includes different operations from planting of trees to the tending, thinning and harvesting of wood. As outlined above, co-products from forestry can be round wood, fibre wood, fuel wood or recreation, to which the environmental effects can be allocated to.

The starting point for allocation in forestry is to specify the main function(s) of the forest under consideration. The following three main types of forestry are distinguished:

1. forest type 1: The aim of the forest is the production of round wood with a high market price; fuel wood and forest residues from tops and branches are seen as waste. Therefore, all environmental effects from forest management are allocated to the amount $\left(\mathrm{m}^{3}\right)$ of round wood and fibre wood. All the other functions (e.g. recreation) of the forest are not considered.

2. forest type 2: The aim of the forest is the production of raw materials for wood products and energy as all these coproducts have a positive economic value. All the environmental burdens are allocated to the amount $\left(t_{d r y}\right)$ of the sum of all co-products. The other functions (e.g. recreation) of the forest are not considered.

3. forest type 3: All different functions of forestry are main goals of forest management besides wood production. These functions can be recreation, welfare, protection, hunting, etc. The environmental burdens related to forest management are allocated to all different functions of the forest and not only to wood production (e.g. on an economic basis).

Beside the description of the forest type, the following forest models for data inventories can be found:

1. model I: investigation of 1 ha of forest from planting (1st year) to final felling (after 70-100 years).

2. model II: annual investigation of a forestry system with a linear distribution of age classes, which means 1 ha for each age class, where the number of ha is determined by the year for final felling (e.g. 100 ha in a system where final felling takes place after 100 years).

3. model III: investigation of a real existing forestry system with distributed age classes and an annual data inventory.

In this context, examples are given from Austria, Finland and Sweden reflecting these different modelling approaches. The forest types 1 and 2 are analysed in combination with the models I, II and III.

Description Austria. For forest type 1 and 2, the Austrian situation is modelled to demonstrate allocation in a forest management system for spruce from planting of trees until the final felling after 100 years for a 1 ha system (model I) and for a 100 ha system (model II) in 1 year, for which the basic figures are given in Table 1.

As an environmental effect, the allocation of $\mathrm{CO}_{2}$ emissions from fossil energy consumption for forest management (planting of trees, three thinnings, final felling, etc.) is shown. In Fig. 1 the cumulated $\mathrm{CO}_{2}$ emissions for the 1 ha system (model 1 ) over 100 years is shown. The allocation on a mass basis of the $\mathrm{CO}_{2}$ emissions from forest management is the same for both models, but differ significantly for the types of forest:

- $49 \mathrm{~kg} / \mathrm{t}_{\mathrm{dry}}$ according to forest type 1 allocation to round wood only,

- $33 \mathrm{~kg} / \mathrm{t}_{\mathrm{dry}}$ according to forest type 2 allocation to all the co-products.

Description Finland. The aim of Finish forestry is mainly to produce round and fibre wood, which corresponds to a mixture of forest type 1 and 2 . About $65 \%$ of the wood residues from thinning and final felling are used for energy production and the remaining $35 \%$ are left in the forest. The annual data inventory is used as basic data for LCA applications (model 3). In Finland, the 1 st thinning occurs after approximately $30-50$ years, the 2 nd thinning after $50-80$ years, and the trees older than 80 years at the final felling. The share of all harvesting operations in Finland in 1999 are 1st thinning 7\%, 2nd thinning $20 \%$ and final felling $73 \%$.

The annual fuel consumption from harvesting operations is inventoried and emissions are further calculated by using

Table 1: Basic data for the forest model I and II

\begin{tabular}{|c|c|c|c|c|c|}
\hline Forest management & $\mathrm{CO}_{2}$ emission & Round wood & $\begin{array}{l}\text { Fibre wood } \\
t_{d r y}\end{array}$ & $\begin{array}{r}\text { Tops and branches } \\
t_{d r y}\end{array}$ & $\begin{array}{c}\text { Total co-products } \\
-t_{\text {dry }}\end{array}$ \\
\hline planting, year 1 & 500 & - & - & - & - \\
\hline 1 st thinning, year 20 & 500 & $0(0 \%)$ & $0(0 \%)$ & $20(100 \%)$ & 20 \\
\hline 2nd thinning, year 35 & 6,000 & $25(25 \%)$ & $65(50 \%)$ & $40(30 \%)$ & 130 \\
\hline 3rd thinning, year 55 & 8,000 & $125(60 \%)$ & $65(30 \%)$ & $20(10 \%)$ & 210 \\
\hline final felling, year 100 & 20,000 & $560(80 \%)$ & $105(15 \%)$ & $35(5 \%)$ & 700 \\
\hline Total & 35,000 & $710(67 \%)$ & $235(22 \%)$ & $115(11 \%)$ & 1,060 \\
\hline
\end{tabular}

Assumptions:

a) planting: 2,000 - 3,500 trees/ha; 1st thinning: $700-1,700$ trees/ha, 2 nd thinning: $500-700$ trees/ha; $3 \mathrm{rd}$ thinning $300-400$ trees/ha; final felling $500-700$ trees/ha

b) year $20: 15 \mathrm{~kg} /$ tree above ground biomass

c) year $35: 220 \mathrm{~kg} /$ tree above ground biomass

d) year $55: 590 \mathrm{~kg} / \mathrm{tree}$ above ground biomass

e) year 100: 1,162kg/tree above ground biomass 


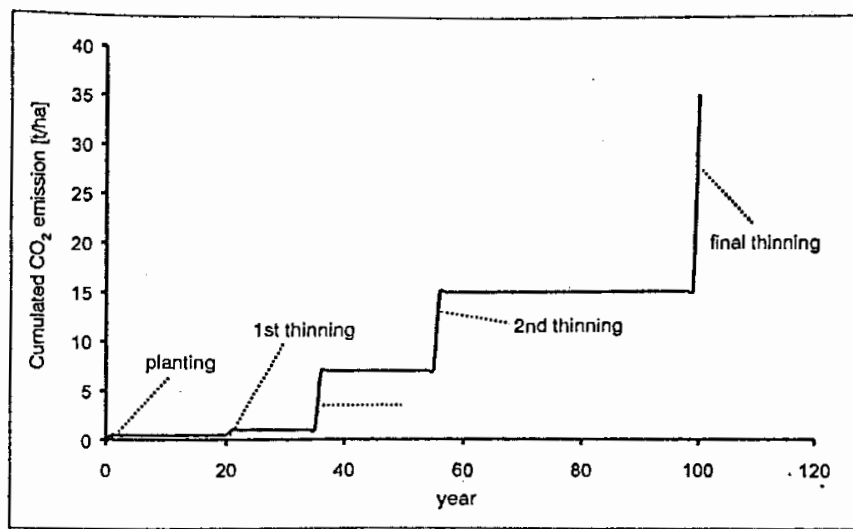

Fig. 1: Cumulated $\mathrm{CO}_{2}$ emissions from forest management for the 1 ha system over 100 years

common emission factors. The collected data are specified for different tree species, different harvesting methods and different wood assortments. These data are set in relation to the annual wood production $\left(\mathrm{m}^{3}\right.$ or $\mathrm{t}$ ) in Finland. Wood used for energy production gets the emissions which occur from handling (e.g. collection, chipping) the residual wood, which is otherwise left in the forest.

Description Sweden. In Sweden, all activities during one year are inventoried (Berg [1]), e.g. the consumption of fuel. Emissions from different activities, e.g. mechanised harvesters are measured. The environmental burdens caused by these activities are allocated by mass basis on the actual wood yield per year and used for LCA. The actual wood yield is the physical harvested and extracted round wood that reaches the mill. The yield is measured in solid cubic meter fresh wood. The LCI data from forestry are available for the different forest activities

Discussion. Forest type 3 causes the difficulty of determining a market price for the social and ecological functions of the forest. Furthermore the stability of the relation of the market prices over time for the products and functions from forestry must be considered when using market prices as an allocation factor. Under Swedish conditions, allocation based on market prices might not to be adequate for allocation in forestry.

The forest inventory data used in Finland and Sweden for LCA give average figures of the actual situation. The comparison of different years shows that there are no significant differences, but in fact teçhological changes can be evaluated, e.g. increasing use of harvester instead of manual harvesting.

Beside the validity of the forest inventory data for one specific year, the data are also very site-specific and strongly dependent on age-classes of the forest, which are not known in detail.

Conclusion. It is necessary to describe the main function(s) of the forest where the raw material is taken out. In some cases different types or functions of forests must be considered and described. Where timber production is the main function of the forestry system, the mass allocation seems practicable and brings reasonable results in an LCA of forest products.
The use of data from national forest data collections is possible if taking limitations (corresponding to average situation) in validity into account. Allocating these data on mass in $\mathrm{m}^{3}$ or $\mathrm{t}$ of wood brings reasonable and practicable results in LCA applications.

\subsection{Sawmill}

Description. Three different approaches for the allocation of energy consumption and $\mathrm{CO}_{2}$ emissions at a sawmill are shown. The model of the process chain is shown in Fig. 2. In the first method, all products are considered as co-products and the volume is used for allocation. The sawmill is subdivided in separate processes like barking, sawing etc. (left side in Fig. 2), with the aim to avoid some allocations. In the second approach, the sawn timber is decided to be the only product and all environmental burdens are allocated to sawn timber. Therefore, the different sawmill processes are aggregated into one process (right side in Fig. 2); the other wooden outputs are waste and regarded free of environmental burden. The third allocation is based on market price (in fact the relative share of proceeds) of the co-products. Sawmill processes must be modelled as one single process to enable a value-based allocation the (right side in Fig. 2), because there are no market prices for intermediate products available (e.g. wet sawn timber).

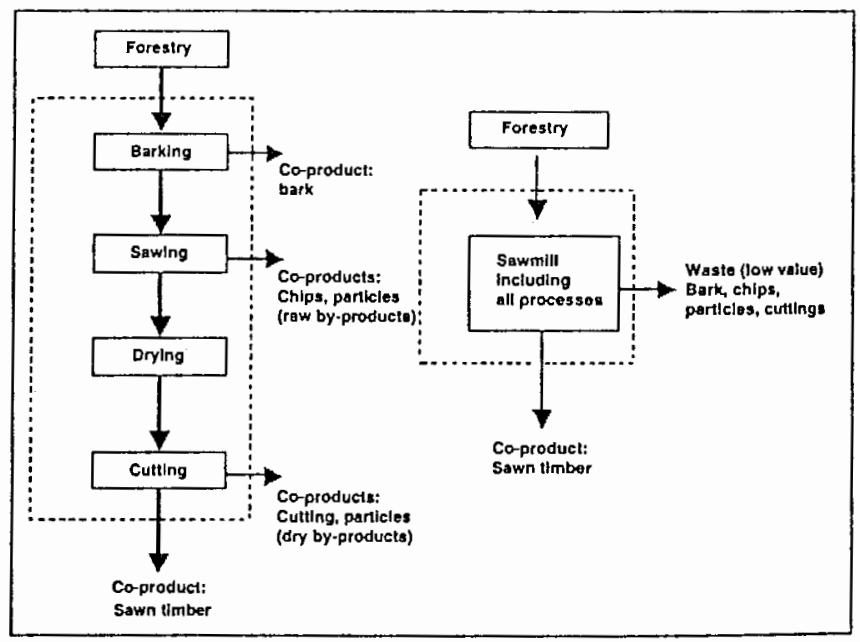

Fig. 2: Process chain and system boundaries for a sawmill with allocation based on volume (left side), and for allocation based on market price and allocation 'all to sawn timber' (right side)

These three allocation options are applied to energy consumption $\left(\mathrm{MJ} / \mathrm{m}^{3}\right)$ and $\mathrm{CO}_{2}$ emissions $\left(\mathrm{kg} \mathrm{CO}_{2} / \mathrm{m}^{3}\right)$ in Table 2, using basic data from environmental declarations for sawn timber in Andersson [2] and Jarnehammar [3].

Discussion. The three different allocation approaches demonstrate their influence on the environmental effects of coproducts from a sawmill, even if the sawn timber is not affected very much. On the contrary, the influence on the dry co-products - chips, side-cuts, particles - are more important. The reason for this is that most of the low value co- 
Table 2: Comparison of the three different allocation approaches for a sawmill

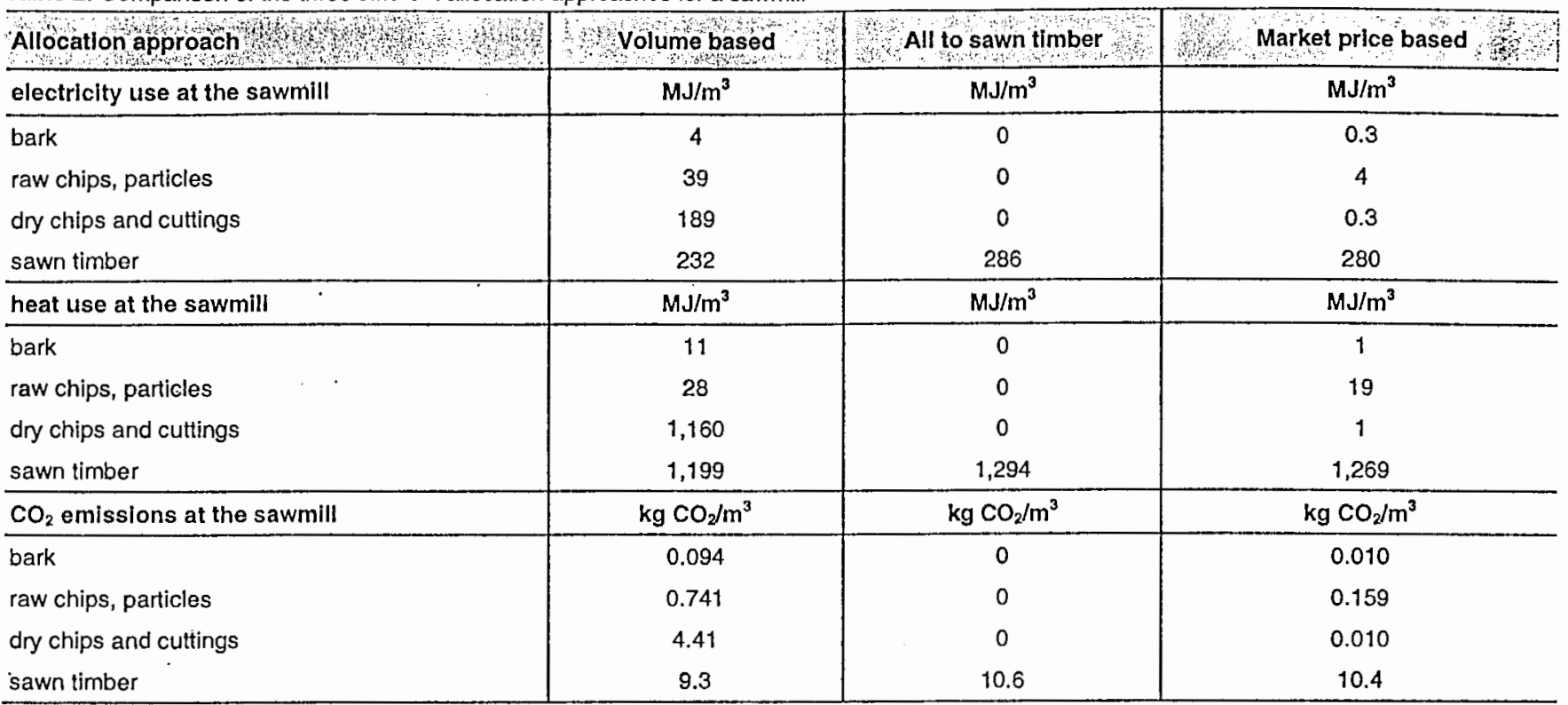

products are leaving the sawmill before the drying operation, and the drying process causes the biggest environmental load in terms of energy and emissions.

In the original LCI in Andersson [2] and Jarnehammar [3], the allocation was first done by subdividing the different processes of the sawmill, and then relating them to the different co-products. When two co-products were sharing a process, a volume-based allocation was used.

Conclusion. Greatest environmental load occurs from the drying operation at the sawmill and most of the low value co-products are leaving the sawmill before the drying process. If only the sawn timber is of interest, either mass- or value-based allocation can be used. Alternatively, to get a rough, but quite reasonably accurate figure, allocate all burdens to the sawn timber.

If mass is used as an allocation factor, the sawmill should first be subdivided into the different processes like debarking, drying, etc.

If value-based allocation is used, the sawmill is modelled as one single process, because economic values are not available for intermediate products. Otherwise, internal prices for intermediate products must be estimated from the cost structure of the sawmill under investigation in Werner [4].

\subsection{Windows}

Description. Wood windows were inventoried as an example for out of ground wood products in the Life Sys Wood project documented in Esser [5] and Richter [6]. As for furniture and other highly manufactured wood products, the material yield of wood window production is very low. A material flow analysis performed as a basis for the life cycle inventory proved that more than $65 \%$ of the wood biomass harvested for a standard window frame leaves the window production line. This fact makes an allocation of harvesting and processing processes to the different wood streams an essential topic of LCA on wood windows, and highly manufactured wood products in general.

Within the project group of Life Sys Wood, it was decided that environmental burdens should be allocated to only those products which are the 'aim' or the 'intended output' of a process. Thus, inventory data was allocated to the window: All residues produced along the material chain were regarded as co-products or waste. The distinction between co-product and waste was made based on the relative economic shares of the outputs of a process.

Discussion and Conclusion. The results of the inventory assessment for this standard version of the solid wood window are presented in Table 3; in this example the impact categories are greenhouse potential and acidification.

The highly negative global warming potential of the wood frames results mainly from the renewable $\mathrm{CO}_{2}$ that is embodied onto the wood residues that are produced along the window production chain. According to the allocation rule, the wood residues are treated as waste, so all upstream interventions including the $\mathrm{CO}_{2}$ uptake are not allocated to them. Although $90 \%$ of the final window frame is incinerated in the disposal processes, thus emitting the bound $\mathrm{CO}_{2}$, the GWP score remains negative.

The acidification potential is mainly related to $\mathrm{NO}_{x}(65 \%)$ and $\mathrm{SO}_{2}$ emissions $(35 \%)$. Significant impacts in this score result from the wood drying process (biomass energy, 30\%),

Table 3: Selected LCIA results of a standard wood window with different allocations

\begin{tabular}{|c|c|c|}
\hline $\begin{array}{l}\text { Wood window frame LCIA } \\
\text { When modelling }\end{array}$ & $\begin{array}{l}\text { GWP } 100 \\
\mathrm{~kg} \mathrm{CO} 2 \text { /window }\end{array}$ & $\begin{array}{l}\text { Acidification } \\
\mathrm{kg} \mathrm{s} \mathrm{S}_{2} / \mathrm{window}\end{array}$ \\
\hline residues as waste & $-24,000$ & 1.85 \\
\hline residues as co-product & $-4,130$ & 1.07 \\
\hline
\end{tabular}


road transports $(30 \%)$ and the production of aluminium billets $(20 \%)$.

In a sensitivity study, it was analysed how these results change when another allocation rule is selected. If residues produced in the forestry (residues from thinning), sawmilling and profiling processes are regarded as co-products instead of waste, the upstream interventions can be allocated between the timber used in the window frame and the residues used outside the window production (e.g. as wood composites, pulp and paper). Allocation is made based on mass for the forestry and sawmill processes, and on economic value for the wood window profiling process (estimating a price ratio of $5: 1$ between the rough window sections and the residues). The same allocation procedure was also applied to the carbon uptake. The results of the sensitivity analysis are shown in Table 3.

The figures show that the categorisation of the process outputs influences the LCIA results significantly. The $\mathrm{CO}_{2}$ potential of the window is reduced to $17 \%$ because the carbon stored in the residues is now allocated to the product systems that use the residues as input material. Acidification, which is linked mostly to $\mathrm{NO}_{x}$ and $\mathrm{SO}_{2}$ emissions, is reduced to $57 \%$, because the transports and energy demand are partitioned between the co-products.

The different allocation approaches underline that allocation is of considerable importance for wood products whose manufacturing processes are causing a relatively low material yield. The big and unrealistic discrepancy in the global warming potential of the calculation presented supports the recommendation that the embodied $\mathrm{CO}_{2}$ as well as the heating value are part of the material mass and thus need to be allocated in multi product systems on a mass basis.

\subsection{Bioenergy}

Description. The aim in Jungmeier [7] is a comparison of greenhouse gas emissions from bioenergy systems and fossil energy systems. The analysed biomass fuels are

1. wood chips and wood logs from thinning and clear cut in forestry

2. bark and wood chips from sawmill

3. wood waste from wood industry, pulp and paper industry and particle board industry

4. wood waste from wood and particle board recycling and

5. waste paper from paper recycling

The comparison is based on the functional unit of greenhouse gas emissions per $1 \mathrm{kWh}$ of heat ( $\mathrm{g} \mathrm{CO}_{2}$-equivalent/ $\mathrm{kWh}$ ). Within the scope of this goal an extension of system boundaries by including the material use of wood for different wood products is not practicable. This means that allocations cannot be avoided and an allocation procedure must therefore be applied. Further on it is assumed that the wood product (e.g. round wood from forestry, sawn timber from sawmill) is the co-product with the higher market price and wood for energy is the co-product with the lower market price. So, all wood used for energy (e.g. tops and branches from thinning, bark from sawmill, waste paper from collection) is regarded as waste with no environmental burdens from previous processes. But all effects directly caused by the energy wood like chipping, transportation or change of the carbon storage pool are included. This allocation procedure was discussed and fixed at the very beginning of the project in an external review by other experts and the customers of the project.

Discussion. This allocation is not tested with other environmental effects like loss of nutrients or biodiversity. This allocation cannot be appropriate for comparisons of material and energetic use of wood (e.g. wood chips from sawmill for particle boards or energy production).

Conclusion. From the experience with this example, it can be recommended that the acceptance for the chosen allocation procedure be obtained from an external expert group or other involved/interested stakeholders during the first phase of an LCA. This allocation is useful for LCA of energy production systems, especially if the wood for energy is available from an increasing production of wood-based products, where the economic purpose is the material use of wood.

\subsection{Combined heat and electricity production}

Description. An LCA is made for the comparison of different technologies for combined heat and power production, whereas a specific heat and electricity demand is defined. Each technology for a combined heat and power plant has a certain relation between the co-products of electricity and heat. First, the electricity demand is satisfied with a specific technology and then the corresponding supply of heat is calculated.

- If the supply of heat is higher than the demand of heat, the 'extra' heat is considered as waste heat

- If the supply of heat is lower then the demand of heat an additional system for heat production alone is added that uses the same fuel as the combined heat and power plant

The necessary amount of fuel and the kind of combined heat and power system determine the environmental effects for comparison. An example is shown in Fig. 3 with the particle emission from heat and electricity production in a typical combined heat and power (CHP) plant run with biomass. The extension of system boundaries means that the functional unit is a 'package' of $0.14 \mathrm{kWh}$ electricity plus $0.86 \mathrm{kWh}$ heat, which reflects the ratio of electricity to heat of $1: 6$. This allocation leads to emissions of $27 \mathrm{mg} /$ $(0.14 \mathrm{kWh}$ electricity and $0.86 \mathrm{kWh}$ heat). This can be compared to any other energy system that supplies the same amount of electricity and heat.

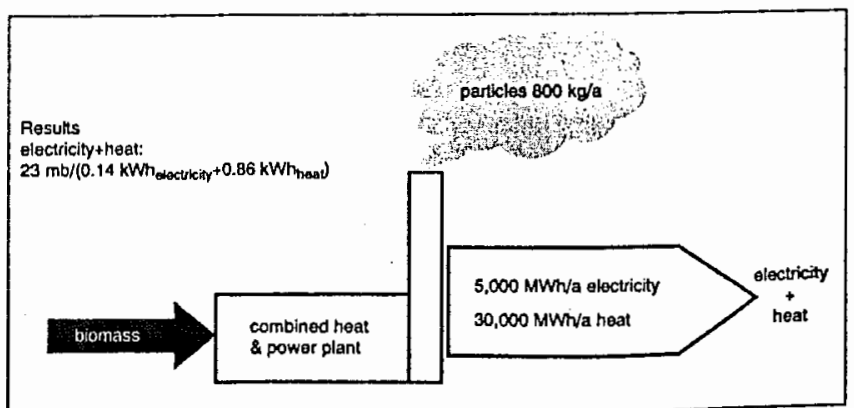

Fig. 3: Example of combined heat and electricity production 
Discussion. With this functional unit of heat and electricity, it is not possible to have a separate value for heat and electricity. Combined heat and power production offers a rise in fuel efficiency, leading to a decrease of environmental burdens emitted per unit useful energy. The comparison of different allocation options between electricity and heat are outlined in detail in Jungmeier [8]. This allocation procedure was also successfully applied in an LCA study, where different bioenergy systems are compared to fossil energy systems for the combined supply of heat and electricity in Jungmeier [7].

Conclusion. It is possible to avoid allocation with combined heat and power production. In the case of a different relationship of the co-products of heat and electricity, an additional system should be added instead of giving credits for substitution. The additional system must be specified. In many cases the relationship of heat and electricity depends on the demand (demand driven) and therefore no credits/ benefits should be given to systems that supply more heat or electricity than predefined by the demand.

\subsection{Recycling}

Description. The aim is a comparison of different end-oflife options for $1,100 \mathrm{~kg}$ of waste particle boards in Frühwald [9]. Recycling and incineration with co-generation of heat are compared. In order to avoid allocation the functional unit for the comparison is $1,190 \mathrm{~kg}$ particle boards and $17,100 \mathrm{MJ}$ of energy produced (Fig. 4). The resource consumption - fresh wood and fresh water - and the environ- mental aspects - waste water - of the energy generation and the fresh fibre production is lower. In this case, the incineration with co-generation of heat is preferable to the recycling of old particle boards.

Discussion and Conclusions. The comparison of the recycling of particle boards and energy production is a typical example where allocation can be avoided by extension of a system boundary. It is demonstrated that even a 'complex' functional unit of material and energy for comparison can lead to very clear results, where one option has significantly lower environmental burdens.

\section{Conclusions}

The following conclusions for LCA of forestry, wood, biofuel and wooden products can be given.

Ten different processes in wood-related LCAs are identified, where allocation problems can occur: forestry, sawmill, wood industry, pulp and paper industry, particle board industry, recycling of paper, recycling of wood-based boards, recycling of waste wood, combined heat and power production, landfill.

The following priorities for allocation are given:

1. Avoid allocation by expansion of system boundaries by combining material and energy aspects of wood, because this reflects the characteristics of wood. This means a funcional unit combining wood products and energy.

2. Substitute energy from wood with conventional energy in the LCA of wood products in order to get the functional unit of the wood product alone, but identify the

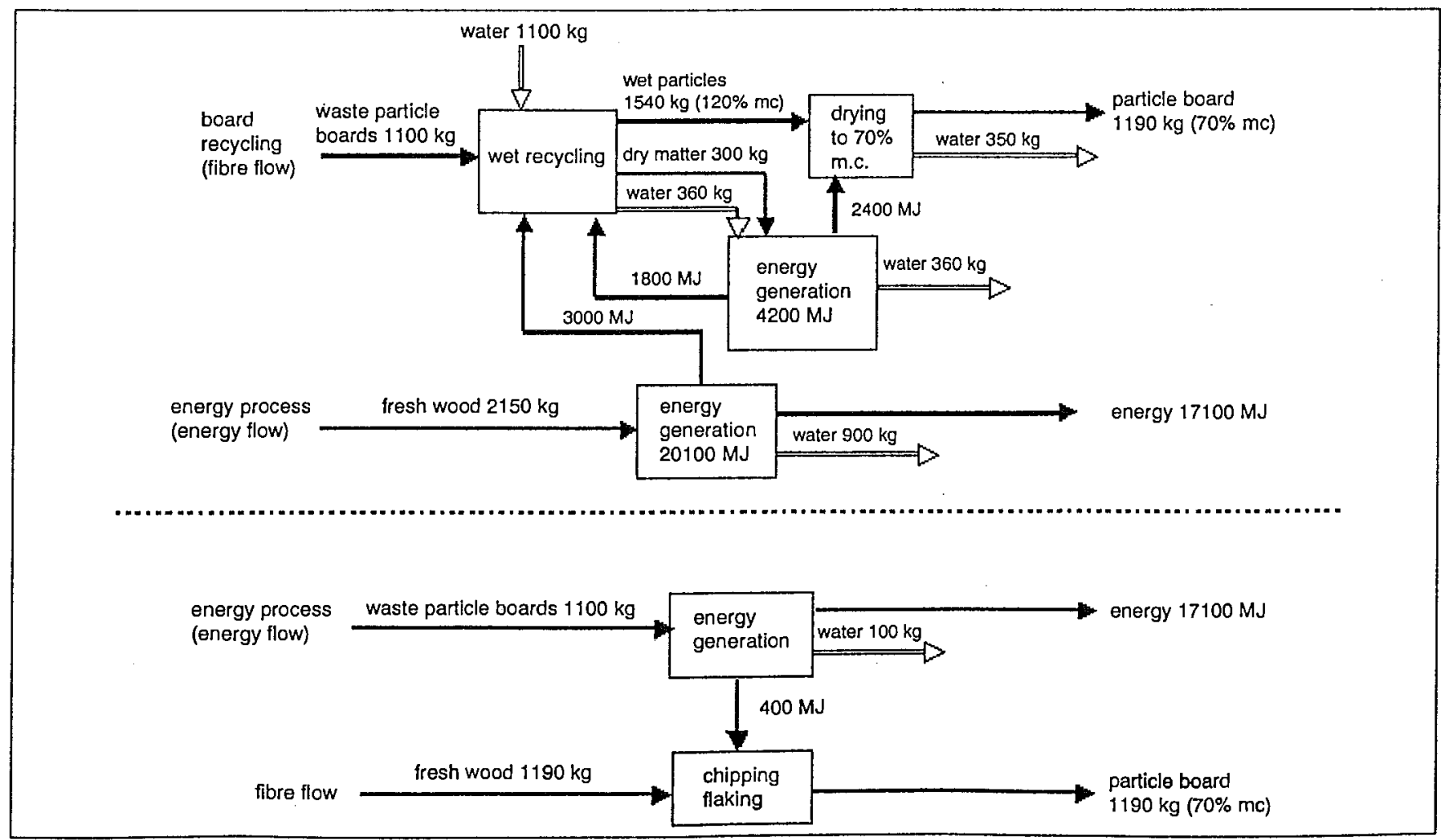

Fig. 4: Comparison of particle-board recycling (above), and energy generation from particle board (adopted from Frühwald 1999) 
criteria for the substituted energy and document the assumptions for the choice of the substituted energy. For transparency reasons of the results, the documentation should also contain the procedure following 1).

3. Substitution of wooden products with non-wooden products in LCA of bioenergy is not advisable, because the substitution criteria can be very complex.

4. In some cases it is not possible to avoid allocation, for which the reasons should be documented.

5. In general, different allocations on mass and economic values (e.g. the relative share of proceeds), for example, are possible within the same LCA.

6. The different allocation options must be analysed and should be documented. In many cases, it seems necessary to make a sensitivity analyses on different allocation options for different environmental effects. It can also be useful to get the acceptance of the chosen allocation procedure by external experts or stakeholders in the starting phase of the LCA.

7. For allocation in forestry, it is necessary to describe the main functions of the forest where the raw material for the LCA is taken out. In some cases different types or functions of forests must be considered and described. Where forestry is a timber production system in an LCA of wooden products, allocation based on mass is practicable and brings reasonable results.

8. Regarding the experiences from the examples, the following most practical allocation for some specific processes are identified:

- forestry: allocation based on mass or volume

- sawmill: mass or volume and market price (relative share of proceeds)

- wooden industry: mass and market price (relative share of proceeds)
Acknowledgements to: Adoll Merl, Francesca Gambineri, Hannes Schwaiger, Helena Wessman, Andreas Windsperger, Staffan Berg, Fred McDarby, Almut Beate Heinrich; National Funds: Bundesamt für Bildung und Wissenschaft, Bern, Switzerland; Federal Ministry of Agriculture, Forestry, Environment and Water Management, Vienna, Austria

\section{References}

[1] Berg S (2001): Personal communication with Mr. Berg from Skogforsk, January 2001

[2] Andersson B-I (1996): Environmental declaration for sawn timber, Trätek

[3] Jarnehammar A (2000): LCA for multi-layer parquet flooring in Life Sys Wood. Trätek

[4] Werner F (2002): Modelling of Wood Products in Life Cycle Assessment with Special Emphasis on Recycling and End-of-life; Model Requirements, Allocation Procedures and Recommendations Derived from LCAs of Railway Sleepers and Particle Board. EMPA reserach report No. 115/48, Dübendorf, Switzerland

[5] Esser P (1999): Life Sys Wood. Consistent Life Cycle Analysis of Wood Products. Final Consolidated Report CHT-RO19S

[6] Richter K (1999): Project Partner Final Report. LCA of Standard Window Frames. EMPA, Dübendorf, Swirzerland

[7] Jungmeier G, Canella L, Spizer J, Stiglbrunner R (1999): Treibhausgasbilanz der Bioenergie - Ein Vergleich der Treibhausgas-Emissionen von Bioenergie-Systemen und fossilen Energiesystemen; (Greenhouse gas balance of bioenergy - A comparison of greenhouse gas emissions of bioenergy systems and fossil energy systems), Institute of Energy Research, Joanneum Research, Graz September 1999

[8] Jungmeier $G$ (2001): Allocation example of combined heat and electricity production published in 'Life cycle assessment of forestry and forest products', ISBN 92-894-1292-5, Belgium 2001

[8a] Jungmeier $G$, Werner $F$, Jarnehammer $A$, Hohenthal $C$, Richter $K$ (2002): Allocation in LCA of Wood-based Products. Experiences of Cost Action E9. Part I. Methodology. Int J LCA 7 (5) 290-294

[9] Frühwald A (1999): Example LCA End of Life: Wood-based Products (example parricle board), presentation at the 5th meeting of Working group 3 'End of life: Recycling, disposal and energy production' of Cost Action E9 'Life cycle Assessment of Forest products', 8-9th November 1999, Hamburg

Received: May 9th, 2001 Accepted: August 5th, 2002 OnlineFirst: August 12th, 2002

Int J L.CA 5 (2) 79-83 (2000)

\section{Economic Allocation in LCA: A Case Study About Aluminium Window Frames}

\section{Frank Werner and Klaus Richter}

Corresponding author: Frank Werner, EMPA, Dübendorf, Überlandstrasse 129, CH-8600 Dübendorf, Switzerland; e-mail: frank.werner@empa.ch

DOI: $\mathrm{http}: / / \mathrm{dx}$.doi.org/10.1065//ca1999.12.008 - A traditional problem in LCA is how to deal with processes where recycled material is used as an input or where the output of a process is further used as raw material in another product system (open-loop recycling). Allocation is needed to partition the responsibility for the environmental impacts caused by the raw material extraction, the recycling and the final disposal of a material over different product systems in some proportional shares. The norm ISO/DIS 14'041:1998 now explicitly allows the use of an economic value as a basis for the allocation of open-loop product systems, where material is recycled into other product systems while undergoing a change in its inherent properties. In a case study for aluminium window frames, an economic allocation procedure for aluminium is developed based on different market prices for secondary materials with different alloy content. Market prices are assumed to reflect the functionality of a material quality within a techno-economic system. Therelore, market prices permit the qualitative description of the degradation of a material over a product system. Based on this qualitative degradation, a 'relative resource consumption' can be defined. This relative resource consumption is used to allocate the environmental impacts related to recycled material entering or leaving the product system under study. The results of the new allocation principle are compared to results of a former study on window frames out of various materi-als, elaborated by EMPA in 1996. The conclusions underline the importance of the recycling of aluminium with a high quality and give some criteria for a more ecological design of aluminium windows. Finaliy, methodological advantages and obstacles of the presented economic allocation procedure are pointed out. 
